\title{
Prevalence and Economic Significance of Bovine Hydatidosis and Cysticercosis in Mekelle Municipality Abattoir, Northern Ethiopia
}

\author{
Getachew T*, Olani W and Sadia H \\ Oromia Livestock and Fieshery Resource Development Bureau, Addis Abeba, \\ Ethiopia
}

*Corresponding author: Getachew Teka, Oromia Livestock and Fieshery

Resource Development Bureau, PO Box 41435, Addis Abeba Ethiopia, Email: gechwon@yahoo.com

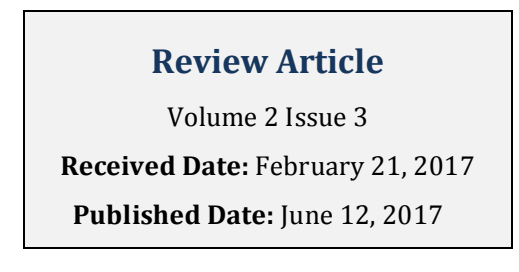

Review Article

Volume 2 Issue 3

Received Date: February 21, 2017

Published Date: June 12, 2017

\section{Abstract}

A cross-sectional study was conducted from November 2009 to March 2010 on cysticercosis (Cysticercus bovis) and cystic echinococcosis in cattle slaughtered at Mekelle municipality abattoir in Tigray region of Ethiopia with over all objectives of determining the prevalence of metacestods and providing the baseline data on their status and socio economic importance in the study area. Accordingly, a total of 1800 randomly selected slaughtered cattle were examined both during ante mortem and postmortem inspection and then a prevalence of 22.2\% (399/1800) for hydatidosis and 4.44\% (80/1800) for cysticercosis observed. The distribution of Cysticercosis in infected organs and tissue showed: masseter muscle and heart (0.2\%), lung $(0.7 \%)$, tongue $(0.4 \%)$ and liver (3.1\%). The logistic regression analysis of potential risk factors revealed that there was statistically insignificant difference in the prevalence of taeniasis between animals from different origin and age ( $\mathrm{P}>0.05)$. Regarding the distribution of hydatid cyst; lung (13\%), liver (8.2\%), spleen $(0.44 \%)$, kidney $(0.17 \%)$ and heart $(0.3 \%)$. Study results indicated that age, body condition and origin have significant effect $(\mathrm{P}<0.05)$ on the prevalence of the disease. A lower percentage of calcified cysts (23.3\%) out of cyst examined and relatively high percentage, $37.8 \%$ and $38.9 \%$ of the total cysts were fertile and sterile, respectively. The total annual economic loss from organ condemnation and carcass weight loss due to hydatidosis and cysticercosis was estimated to be 930,918.52 ETB. The result of this study revealed that metacestode is the major disease causing direct and indirect economic losses significantly in the study area. Control strategies should be instituted taking into account the social, cultural and economic condition at the study area.

Keywords: Abattoir; Bovine; Cysticercosis; Economic losses; Hydatidosis; Mekelle; Metacestode; Prevalence

\section{Introduction}

Livestock largely backs the agricultural sector of the country both as means of drought power for crop agronomy, food and income generation on its own right. Ethiopia's livestock population is estimated to be 40.9 million head of cattle, 25.5 million head of sheep, 23.4 million goats, 2.7 million horse, 5 million donkeys and about 2.3 million camels [1].

In Ethiopia ruminant livestock are important source of income for rural communities and are one of the 
nation's major sources of foreign currency from export. However, this great potential is not properly exploited mainly due to prevailing traditional management, limited genetic potential and rampant animal disease. Of the diseases that cause serious problem, parasitism represents a major impact on livestock production in the tropics [2]. Among the parasitic diseases, metacestode in domestic ruminants inflicts enormous economic damage due to the condemnation of affected organs and lowering of meat, milk and wool production. The metacestode is passively transferred to the definitive host when the latter ingests the infected intermediate host [3].

Echinococcosis or hydatidosis is a zoonotic and economically significant disease caused by adult or larval (metacestode) stages of cestodes belonging to the genus Echinococcus and the family Taenidae. The parasite are perpetuated in life cycles with carnivores as definitive hosts, which harbor the adult egg producing stage in the intestine and intermediate host animals, in which the infective metacestode stage develops after oral infection with the eggs. The cestode Echinococcus granulosus is the causative agent of cystic hydatid disease or hydatidosis, which is recognized as one of the major zoonoses affecting both human and domestic animals in various parts of the world [4]. Hydatid disease in human is a very serious disease and no person should consider them selves immune from this disease. The disease is caused by hydatid cyst growing in the body and the sites commonly infected in human are liver, lungs and peritoneal cavity [5]. The most serious consequence of hydatid disease is when the cyst ruptures and causes anaphylactic reactions, which may be fatal [6].

The wide variety of animal species that can act as intermediate host and the domestication and the spread of some of those animals from Europe to other parts of the world have given Echinococcus granulosus a world wide distribution. It has been extensively studied in a number of geographical areas and is now present in Asia, Africa, South and Central America and the Mediterranean region [7]. Human behaviors play a significant role in the epidemiology of hydatidosis and the dynamics of transmission differs between the dog and its normal intermediate hosts and human host. Land tenure, social development and attitude to dogs are important factors. For instance ethnic and cultural factors have been found responsible for high transmission rates for hydatidosis among Eskimos, among Basques in California and between Turkana in Kenya [8].
In Ethiopia hydatidosis has been known and documented as early as 1970s. It is the major cause of organ condemnation in most Ethiopian abattoirs and slaughter houses [9-13] and leads to huge economic losses [14]. Have studied the occurrence of the infection in stray dogs and cattle in some locations in Addis Ababa and reported a prevalence rate of $10.2 \%$ and $31.9 \%$, respectively. In Ethiopia it is a common practice to feed dogs and cats with hydatid infected organs; hence human beings facilitate the maintenance of the life cycle progression in the environment. Despite high prevalence of the disease in domestic ruminants and dogs, it seems that the required attention is not given to it [14]. Hagos Y [13] reported the occurrence of hydatidosis in cattle slaughtered at Mekelle municipality abattoir and reported prevalence rate of $32.1 \%$ with fertility rate of $29 \%$ with an estimated annual loss of 129, 934 Birr. Jobire Y [15] Found prevalence rate of $46.5 \%, 25.7 \%$ and $24.3 \%$ of hydatid cyst in cattle slaughtered in Debre Zeit, South Omo and Gonder, respectively.

Taeniasis is intestinal infection with the adult stage of large tapeworm in humans. Cattle and pigs are the intermediate hosts for Taenia saginata and Taenia solium, respectively. Egg of Taenia saginata pass in the stool of an infected person into the ground (grasses) and cattle become infected by ingestion of feed-stuff containing ova passed from infected human. A wide variety of tapeworms (cestodes) occur in domestic animals. Presence of larval stage of these hosts is of public health and economic significance. The tapeworm problem is more serious in tropics because the consumption of under cooked or raw meat is common in countries of such regions, one of such parasites is Taenia saginata which represents true zoonoses and is a very common amongst people who preferred beef in an uncooked or raw state [16].

In Ethiopia Taenia saginata infection is very common as raw beef is customarily consumed by most high land inhabitants. Cattle raised on free range become often infected through contamination of grazing area with human stool [17].

Mamo E [18] reported the prevalence of Taeniasis to be 10 to $70 \%$. The prevalence of Cysticercus bovis was reported to be $26.3 \%$ and $7.2 \%$ in cattle slaughtered at Awasa and Mekelle municipality abattoir, respectively $[19,20]$. In the world there are some countries, which are by now free from the disease due to their sound control programs; however, metacestode is still a major public health hazard and cause of economic loss due to condemnation of organs in Ethiopia. 
Therefore this study has been carried out with the following objectives:

- To evaluate the prevalence of metacestode in cattle slaughtered at Mekelle municipality abattoir,

- To determine the economic losses due to condemnation of the organs and

- To gather the base line data that will help in designing the control and prevention strategies of Taenia saginata or cysticercosis and hydatidosis.

\section{Materials and Methods}

\section{Study Area and Animals}

The study was conducted at Mekelle municipality abattoir. Mekelle is the capital city of Tigray national regional state and it is located at $39^{\circ} 29^{\prime} \mathrm{E}$ and $13^{0} 10^{\prime} \mathrm{N}$. Mekelle has an altitude of 2000 m.a.s.l and it is suited $778 \mathrm{~km}$ north of Addis Ababa. The climate of the study area conforms to that of Ethiopian highlands. The mean annual rain fall of the study area is $628.8 \mathrm{~mm}$ and the rain is associated with north and south oscillation of Inter-tropical conversion zone (ITZ). The rain fall is bimodal with the short rainy season occurring from March to May and the long rainy season from June to August, followed by the dry season from middle of September to February [21].

The annual minimum and maximum temperature is $11.8^{\circ} \mathrm{C}$ and $29.94^{\circ} \mathrm{C}$, respectively. Mekelle municipality abattoir is the oldest and largest abattoir in the region. It was established in 1964 and an average 8,206 cattle is slaughtered annually for meat consumption. The slaughtered animals originate from Tigray, Afar and north Wollo areas [21].

\section{Sampling and Sample Size}

Simple random sampling method was used for sampling using the $95 \%$ confidence interval. The sample size was determined by the formula.

$\mathrm{N}=1.96^{2} \mathrm{P}_{\exp }\left(1-\mathrm{P}_{\exp }\right) / \mathrm{d}^{2}$

Where: N-required sample size

$\mathrm{P}_{\text {exp }}$-expected prevalence

d -desired absolute precision (Thrusfield, 1991).

\section{Study Methodology}

The study design was a cross-sectional epidemiological study done on three randomly selected days of the five slaughter days of a week from November 2009 to March 2010. All cattle slaughtered during each visit days were sampled. The data was collected through ante mortem and postmortem inspection of animals, examination of cyst fertility and viability of protoscolices and the cyst of Cysticercus bovis were also tested for their viability. Moreover recording of condemned organs was done in order to asses the economic losses were also undertaken.

Ante mortem and postmortem inspection: The crosssectional study which involves active abattoir survey was conducted during routine meat inspection activity on randomly selected 1800 cattle slaughtered at Mekelle municipal abattoir. Accordingly, the study animals were selected during ante mortem inspection (AMI) and the related risk factors such as sex, age, and origin, breed and body condition were recorded before slaughtering on specially designed sheet. The animals were ranked as poor, medium and good depending on their body condition score. Origin of the slaughtered animals was also recorded as highland (above 1500m.a.s.l) and lowland (below1500m.a.s.l). Identification of the study animals was done with the help of enumerated marks on their body surfaces using ink and this marking were transferred to all visceral organs after slaughter and each predilection sites (organs) for the metacestodes were also carefully followed and inspected for the presence of the respective larvae.

During postmortem examination, a thorough visual inspection, palpation and systematic incision of each visceral organ particularly the liver, lung, kidney, heart and spleen was carried out and infected organs were taken to the laboratory and all Hydatid cysts found in the organs were collected to conduct cyst count, cyst size measurements, to test cyst fertility and viability [22].

After each hydatid cyst is collected from different internal organs, the cyst wall was penetrated by a needle and opened with scalpel and blades. Then the contents were transferred into a sterile test tube. The cyst volume was arbitrarily classified into three categories: small when the volume is less than $6 \mathrm{ml}$, medium when the volume is between $6 \mathrm{ml}$ and $20 \mathrm{ml}$ and large when the volume is more than $20 \mathrm{ml}$. Based on the presence or absence of broad capsule containing protoscolices in the hydatid fluid, cysts were classified as fertile or infertile. The infertile cysts were further classified as sterile (fluid filled cyst without any protoscolices) and calcified (cyst already calcified ).To determine viability of protoscolices, a drop of the sediment consisting of the protoscolices was placed on a microscopic slide and equal amount of $0.1 \%$ aqueous eosin solution was added to the slide and then covered with cover slip and observed under microscope objective of $\mathrm{X} 40$ with the principle that viable protoscolices should completely or partially exclude the dye while the dead ones take it up [23]. 


\section{Open Access Journal of Veterinary Science \& Research}

The predilection site of cysticercosis was inspected as follows: for masseter muscle deep linear incisions were made parallel to the mandible, the tongue was examined from base to apex; the heart was incised from its base to the apex to open the pericardium and incision was also made in the cardiac muscle for detailed examination. In addition deep, adjacent and parallel incisions were made above the point elbow in the shoulder muscle.

Examination of the kidneys, liver and lung were also conducted accordingly. All the positive samples were transported to the Mekelle University College of Veterinary Medicine, parasitology laboratory for confirmation of cyst viability. The cysts were incubated at $37^{\circ} \mathrm{C}$ for $1-2$ hours. After this the scolex was examined under microscope by pressing it between two glass slides. The cysts were recorded as viable if the scolex evaginate during the incubation period and the scoleces were checked to classify them as Tania saginata metacestode or others based on the size of Cysticercus bovis, absence of hook on the rostellum of the evaginated cyst [24].

Assessment of economic losses: An attempt was also made to estimate the annual economic losses from hydatidosis and cysticercosis in cattle taking into account the direct losses from cost of offal condemned and from weight loss. The retail market price of average size offal (liver, lung, heart, kidney, spleen) and information on the cost of $1 \mathrm{~kg}$ of beef were obtained from local butchers. Average annual slaughter rate of cattle at Mekelle municipality abattoir was estimated based on a retrospective analysis of five years data and estimated 5\% carcass weight loss was considered (Polydorous, 1981). Average carcass weight of Ethiopian local breed cattle is estimated as $126 \mathrm{~kg}$ [25]. The total economic loss was calculated as the summation of cost offal condemned plus the cost of carcass weight loss [26].

1. Annual cost of offal condemned $=\left(\mathrm{CSR} * \mathrm{P}_{\mathrm{HLu}}{ }^{*} \mathrm{C}_{\mathrm{PLu}}\right)+$ $\left(\mathrm{CSR} * \mathrm{P}_{\mathrm{HLi}} * \mathrm{C}_{\mathrm{PLi}}\right)+\left(\mathrm{CSR} * \mathrm{P}_{\mathrm{HHe}} * \mathrm{C}_{\mathrm{PHe}}\right)+\left(\mathrm{CSR} * \mathrm{P}_{\mathrm{HKi}} * \mathrm{C}_{\mathrm{PKi}}\right)$ $+\left(\mathrm{CSR} * \mathrm{P}_{\mathrm{HSp}} * \mathrm{C}_{\mathrm{PSp}}\right)$

2. Annual cost of carcass weight losses $=5 \% * \operatorname{CSR} * \mathrm{P}_{\mathrm{H}} *$ $\mathrm{P}_{\mathrm{C}} * \mathrm{C}_{\mathrm{PB}} * 126 \mathrm{~kg}$.
Where:

$\mathrm{CSR}=$ Average number of cattle slaughtered per year $=8,260$

$\mathrm{P}_{\mathrm{HLu}}=$ Percentage of lung condemned $=31.83 \%$

$\mathrm{C}_{\mathrm{PLu}}=$ Mean cost of one bovine lung in Mekelle $=9 \mathrm{birr}$

$\mathrm{P}_{\mathrm{HLi}}=$ Percentage of liver condemned $=15.29 \%$

$\mathrm{C}_{\mathrm{PL}} \mathrm{i}=$ Mean cost of one bovine liver in Mekelle $=60 \mathrm{birr}$

$\mathrm{P}_{\mathrm{HHe}}=$ Percentage of heart condemned $=0.25 \%$

$\mathrm{C}_{\mathrm{PHe}}=$ Mean cost of one bovine heart in Mekelle $=15$ birr

$\mathrm{P}_{\mathrm{HKi}}=$ Percentage of kidney condemned $=0.25 \%$

$\mathrm{C}_{\mathrm{PHKi}}=$ Mean cost of one bovine kidney in Mekelle $=10$ birr

$\mathrm{P}_{\mathrm{HSp}}=$ Percentage of spleen condemned $=1.5 \%$

$\mathrm{C}_{\mathrm{PSp}}=$ Mean cost of one bovine spleen in Mekelle $=1 \mathrm{birr}$

$5 \%=$ Carcass weight losses in individual animal due to metacestode

$\mathrm{P}_{\mathrm{H}}=$ Prevalence of hydatidosis in Mekelle $=22.17 \%$

$\mathrm{P}_{\mathrm{C}}=$ Prevalence of cysticercosis in Mekelle $=4.44 \%$

$\mathrm{C}_{\mathrm{PB}}=$ Average market price of one $1 \mathrm{~kg}$ of beef in Mekelle $=60 \mathrm{birr}$.

Data analysis: Abattoir data was collected and recorded on specially designed forms and preliminary analysis was done in Microsoft excel. The out come variables for the abattoir study were cases Cysticercus bovis and Hyadit cyst detected during routine postmortem inspection at Mekelle municipal abattoir. Logistic regression was employed to analyze the association of the occurrence of the two diseases with the potential risk factors like origin, age, body conditions using GMP 5 statistical soft ware.

Multivariate analysis for the risk factors during study period was used in which the degree of risk factors association between the diseases occurrence and the risk factors was analyzed using odd ratios.

\section{Results}

\section{Prevalence of Hydatidosis and Cysticercosis}

Based on the routine meat inspection conducted at Mekelle municipal abattoir on the 1800 cattle during the study period, the prevalence of Hydatid cyst and Cysticercus bovis was found to be $22.17 \%(399 / 1800)$ and $4.44 \%(80 / 1800)$, respectively indicating the higher prevalence of than cysticercus bovis (Table 1). 


\section{Open Access Journal of Veterinary Science \& Research}

\begin{tabular}{|c|c|c|c|c|c|}
\hline \multirow{2}{*}{ Risk factors } & \multirow{2}{*}{$\begin{array}{c}\text { No of animals } \\
\text { examined }\end{array}$} & \multicolumn{2}{|c|}{ Hydatid cyst } & \multicolumn{2}{c|}{ Cysticercus bovis } \\
\cline { 3 - 6 } & & No of positive & Percent (\%) & No of Positive & Percent (\%) \\
\hline Origin & & & & & \\
\hline Highland & 815 & 160 & 19.63 & 37 & 4.54 \\
\hline Lowland & 984 & 239 & 24.29 & 43 & 4.37 \\
\hline Age & & & & & \\
\hline $2-5$ years & 320 & 47 & 14.69 & 15 & 4.69 \\
\hline$>5$ year & 1480 & 352 & 23.78 & 65 & 4.39 \\
\hline Body condition & & & & & 17 \\
\hline Poor & 110 & 41 & 37.7 & 19 & 17.27 \\
\hline Medium & 1400 & 302 & 21.57 & 51 & 3.64 \\
\hline Good & 290 & 56 & 19.31 & 10 & 3.45 \\
\hline
\end{tabular}

Table 1: Summery of risk factors for the occurrence of Hydatid cyst and Cysticercus bovis at Mekelle abattoir.

\section{Risk Factors}

Hydatid cyst Table 2 shows the association between the prevalence of bovine hydatidosis in cattle and risk factors. Accordingly, statistical analysis with GMP 5 revealed the significant difference in the prevalence of hydatid cyst between animals from different origins ( $\mathrm{p}<$ $0.05)$, age $(\mathrm{P}<0.001)$ and also there is significance difference on the basis of body condition score $(\mathrm{P}<$ $0.05)$, which was graded as poor, medium and good . Thus, hydatidosis was more likely to occur in animals from lowland when compared to animals originated from highland, which was $24.29 \%, 19.63 \%$ respectively. Additionally, infection rates on the basis body condition score, which were found to be $37.27 \%, 21.57 \%$, and $19.31 \%$ so that body condition score was inversely related to infection. Moreover, hdatid cyst was more likely occurred in animals of older age (greater than five years age) than adult age (two to five years), which were $23.78 \%$ and $14.69 \%$ respectively.

\begin{tabular}{|c|c|c|c|c|c|}
\hline Risk Factors & $\begin{array}{c}\text { No of animals } \\
\text { examined }\end{array}$ & No of positive & Percentage (\%) & $X^{2}$ & P-value \\
\hline \multicolumn{6}{|c|}{ Origin } \\
\hline Highland & 815 & 160 & 19.63 & 17.215 & 0.028 \\
\hline Lowland & 984 & 239 & 24.29 & & \\
\hline \multicolumn{7}{|c|}{ Age } \\
\hline $2-5$ years & 320 & 47 & 14.69 & 19.366 & 0.001 \\
\hline$>5$ years & 1480 & 352 & 23.78 & & \\
\hline \multicolumn{7}{|c|}{ Body condition } \\
\hline Poor & 110 & 41 & 37.27 & 26.177 & 0.001 \\
\hline Medium & 1400 & 302 & 21.57 & & \\
\hline Good & 290 & 56 & 19.31 & & \\
\hline
\end{tabular}

Table 2: Prevalence of hydatidosis based on age, origin and body condition.

A total of 399 cysts were examined to identify cyst fertility. From these, 151(37.84\%), 155(38.85\%), 93(23.31\%) were identified as fertile, sterile, and calcified respectively. Of the fertile cysts, $101(66.88 \%)$ were viable. Fertile cysts were mostly occurred on lungs, which were $102(67.55 \%)$ of the whole fertile cysts. Sterile cysts were also mostly found on lungs, which were $103(66.45 \%)$ of the whole sterile cysts. However, most of cysts in the liver were found calcified which were 63(67, 74\%) (Table 3). 


\section{Open Access Journal of Veterinary Science \& Research}

\begin{tabular}{|c|c|c|c|c|c|c|}
\hline Hydatid cyst type & Heart & Kidney & Liver & Lung & Spleen & Total (\%) \\
\hline Calcified & $1(0.25 \%)$ & $0(0.00 \%)$ & $63(15.75 \%)$ & $29(7.27 \%)$ & $0(0.00)$ & $93(23.31 \%)$ \\
\hline Non viable & $1(0.25 \%)$ & $0(0.00 \%)$ & $16(4.01 \%)$ & $32(8.02 \%)$ & $1(0.25 \%)$ & $50(12.53 \%)$ \\
\hline Sterile & $0(0.00 \%)$ & $1(0.25 \%)$ & $48(12.03 \%)$ & $103(25.81 \%)$ & $3(0.75 \%)$ & $155(38.85 \%)$ \\
\hline Viable & $3(0.75 \%)$ & $2(0.5 \%)$ & $22(5.51 \%)$ & $70(17.54 \%)$ & $4(1.00 \%)$ & $101(25.31 \%)$ \\
\hline
\end{tabular}

Table 3: Hydatid cyst type by organ involved.

Cysticercus bovis; Table 4 Shows the association between prevalence of bovine cysticercus in cattle and different risk factors. Accordingly, statistical analysis with the same software were revealed the significance difference in the prevail of bovine cysticercosis based on body condition score examined and it was found $17.27 \%(19 / 110), 3.64 \%(51 / 1400)$ and $3.45 \%($ $10 / 210$ ) respectively, as poor, medium, and good.

The differences of prevalence between them were found to be statistically significant $(\mathrm{P}<0.005)$. The percent positivity of Cysticercus bovis in cattle belonging to highland area and lowland area was also calculated and found to be $4.54 \%(37 / 815)$ in highland cattle and $4.37 \%(43 / 984)$ in cattle of lowland area. However, this difference was not statistically significant $(\mathrm{P}>$ 0.05).

The prevalence of Cysticercus bovis was also assessed based on the age group of the cattle examined and it was found to be $4.39 \%(15 / 320)$ for two to five years and $4.39 \%(65 / 1480)$ for the greater than five years cattle. The difference of prevalence between two age groups was found to be statistically insignificance $(\mathrm{P}>0.05)$.

\begin{tabular}{|c|c|c|c|c|c|}
\hline Risk Factors & $\begin{array}{c}\text { No of Animals } \\
\text { Examined }\end{array}$ & No of Positive & Percent (\%) & $X^{2}$ & P value \\
\hline \multicolumn{7}{|c|}{ Origin } \\
\hline Highland & 815 & 37 & 4.54 & 0.271 & 0.965 \\
\hline Lowland & 984 & 43 & 4.37 & & \\
\hline \multicolumn{7}{|c|}{ Age } \\
\hline $2-5$ years & 320 & 15 & 4.69 & 1.001 & 0.801 \\
\hline$>5$ years & 1480 & 65 & 4.39 & \\
\hline \multicolumn{7}{|c|}{ Body Condition } \\
\hline Poor & 110 & 19 & 17.27 & 15.514 & 0.017 \\
\hline Medium & 1400 & 51 & 3.64 & & \\
\hline Good & 290 & 10 & 3.45 & & \\
\hline
\end{tabular}

Table 4: Prevalence of cysticercosis based on age, origin and body condition.

Viability of the cysts was also assessed on 30 cysts separated from organs of 11 cattle out of 80 positive animals. Out of these only in seven animals the scolex of the cyst evaginated. Evagination of scolex in viable cysts normally took place within 1-2 hours [17].

\section{Anatomical Distribution of Cysts}

Analysis of the active abattoir survey showed that there was a significant variation in the anatomical distribution of cysticercosis and hydatidosis in organs inspected .Of the organs examined, the highest proportion of the Cysticercus bovis were observed in the liver $(3.1 \%)$ followed by lungs $(0.7 \%)$ and tongue $(0.4 \%)$, masseter muscle and heart muscle $(0.2 \%)$ where as the highest proportion of Hydatid cyst was recorded in the lung $(13 \%)$ followed by liver $(8.28 \%)$, spleen $(0.44 \%)$, heart $(0.28 \%)$ and kidney $(0.17 \%)$ (Table 5). 


\section{Open Access Journal of Veterinary Science \& Research}

\begin{tabular}{|c|c|c|c|}
\hline \multirow{2}{*}{ Organs } & \multirow{2}{*}{ Total Animal Examined } & \multicolumn{2}{|c|}{ Number (\%) Positive } \\
\cline { 3 - 4 } & & Hydatid cyst & Cysticercus bovis \\
\hline \multirow{2}{*}{ Masseter muscle } & 1800 & 0 & $3(0.2 \%)$ \\
\hline Tongue & 1800 & 0 & $7(0.4 \%)$ \\
\hline Liver & 1800 & $149(8.28 \%)$ & $55(3.1 \%)$ \\
\hline Heart & 1800 & $5(0.28 \%)$ & $4(0.2 \%)$ \\
\hline Lung & 1800 & $234(13 \%)$ & $12(0.7 \%)$ \\
\hline Kidney & 1800 & $3(0.17 \%)$ & 0 \\
\hline Spleen & 1800 & $8((0.44 \%)$ & 0 \\
\hline
\end{tabular}

Table 5: Proportion of Carcass and organ Infected with Hydatid cyst and Cysticercus bovis

\section{Economic Loss Due to Organ Condemnation}

A total of 148 lungs, 81 livers, 3 hearts, 6 spleens and 2 kidneys were condemned due to metacestodes (hydatidosis and cysticercosis) with an economic loss $23,662.42,75,777.24, \quad 309.75,206.5,123.9$ ЕТВ respectively. This was calculated from mean retail market price of cattle liver (60 birr), lung ( 9 birr), heart (15 birr), kidney (10 birr), spleen (1 birr) and the total number of organs condemned during the study period. On the other hand annual economic loss was determined by considering annual slaughter rate of cattle and prevalence of hydatidosis and cysticercosis per organ, and was calculated to be 100,079.812 losses per annum.

\section{Economic Loss due to Carcass Weight Loss}

A 5\% carcass weight loss due to hydatidosis [26] was considered have to estimate the economic loss and computed result showed a loss of 830,838.78 ETB per annum. Therefore, the total estimated economic loss in cattle slaughtered at Mekelle municipality abattoir due to hydatidosis and cysticercosis was estimated to be 930,918.52 ETB.

\section{Discussion}

Hydatidosis and cysticercosis are known to be important in livestock and public health in different parts of the world and different workers in different geographical areas have reviewed their prevalence and economic significance. It is a problem of significant order meriting attention and implementation of control program. However, for the establishment of a control strategy, detailed information on local epidemiology and significance of the disease must be known.

Hydatid cyst; the current study revealed that hydatidosis is highly prevalent and rank first position among parasites causing considerable direct and indirect economic losses in the study area. Hydatidosis is primarily responsible for condemnation of liver and lungs causing significant economic losses.
In the current study, the prevalence rate of hydatidosis was calculated to be $22.17 \%$, which is within range of official abattoir reports on hydatidosis (5-33\%) as reported by Solomon H [28]. This finding is slightly in agreement with finding of Mersie A [9] (20.5\%) in eastern Ethiopia, [29] (19.9\%) at Mekelle, [30] (14.7\%) in Nigeria. However, the prevalence of this study was lower than the finding of [13] (32.12\%), [26] $(33.6 \%)$ in same study area in Mekelle.

The prevalence studies on hydatidosis have shown variation in different geographical areas ranging from low up to very high .Low prevalence rate were reported in Ethiopia from Debre Berhan 7.2\% [31], in Libya 5.6\% [32] and in Sudan 8.11\% [33].

Moderate to high prevalence rates were reported from Gonder $24.3 \%$ and $37.7 \%$ [34, 35] respectively. Kenya 28.4\% [36], South Wollo 28.3\%, [37], Nekemte $31.2 \%$ and $36.07 \%[38,39]$ respectively and Awasa $34.3 \%$ [40].

In other regions of Ethiopia very high prevalence rates were recorded which include [41] in Debrezeit (46.5\%), [42] in Arsi region (54.8\%), [43] in Bahirdar (54.9\%), [44] in Robe (63\%) and [45] around Ticho (89\%).

Generally, prevalence rate of bovine hydatidosis in the country is in the moderate to high range and the present finding (22.17\%) is comparable slightly to the moderate rates recorded in different regions of the country. The variation in prevalence in different countries and regions may be attributed mainly to strain differences of Echinococcus granulosus that exist in different geographical situation [30]. Moreover, other factors like difference in culture, social activities and attitude to dogs in different regions may contribute to these variations [23].

In this study statistical analysis revealed significance difference in prevalence of Hydatid cyst between animals of different origins, age and body conditions. 
Thus, hydatidosis was more likely to occur in animals from lowland $(\mathrm{P}<0.05)$. It has a broad geographical distribution; it is cosmopolitan in distribution with highly endemic areas in Africa [3].

The result also indicated that there is significance difference $(\mathrm{P}<0.05)$ between body condition score and cyst burden. Animals having poor body condition were found to have high cyst burden. The poor body condition among animals is between probably reflections of the effect of relatively high cyst burden.

Polydorous K [27] explained that in moderate to severe infestation the parasite may cause retarded performance and growth, reduced quality and yield of meat and milk as well as live weight loss. For example, he estimated a $5 \%$ and $16 \%$ live weight loss in Yugoslavia and Bulgaria respectively.

One of the focuses of this study was estimating the rate of infection of hydatidosis in different age groups of cattle. Thus, animals with more than five years of age (old) were highly affected. This is may be due to longer exposure time the difference in infection rate raised. The result of this study concurs with that of Fikre I [46] and Hagos Y [13].

Anatomically, proportion of hydatid cyst occurs predominantly in lungs and liver of cattle that was 13\% and $8.28 \%$ respectively. That is similar to what Mersie A [9] and Jobire Y [15] reported. Immature parasites have no selective affinity for any particular organ, and filtering action of capillaries controls location of hydatid cyst in animals. This is justified by the fact that lungs and liver posses the first greater capillaries which act as partial barrier, for the ingested hexacanth embryos which adopt the portal vein route and primarily negotiates the hepatic and pulmonary system sequentially before any other peripheral organ invasion, but onchosphere which traverse these will reach the systemic circulation and hydatids have been found in many organs and tissues [47].

Lungs were more infected than liver, which is in agreement with Mersie A [9] Hagos Y [13] report. All cysts encountered were unilocular indicating that it is the cystic stage of Echinococcus granulosus that by far the most common type is found in feed animals [48].

A lower percentage of calcified cysts $(23.31 \%)$ were identified out of the total cysts examined and relatively high percentage of the total cysts (37.84\%) and $(38.85 \%)$ were identified as fertile and sterile respectively. The variation in fertility, sterility and calcification was described as strain difference by Arene FOI [30].
In agreement with result of fertility rate was higher among the cysts of lungs than liver. It has been stated that relatively softer consistency of lungs allow easier development of the pressure cyst and fertility of Hydatid cysts may show a tendency to increase in advanced age of the host. This may be related with reduced immunological compatibility of the hosts at their old ages of infection [49].

Cysticercus bovis; most and larval tapeworm infection causes little or no disease. However cysticercosis causes economic loss through condemnation of infected meat and offal [50]. Bovine cysticercosis usually does not cause much morbidity or mortality among cattle, but it does cause serious economic problems in the endemic areas due to the condemnation of meat or down grading of carcasses in light infectious, [36] contributing to constraint in food security and safety. The economic losses as a result of condemned and downgraded carcasses due to treatment or processing of carcasses for human consumption are substantial [51]. In East Africa, Taenia saginata cysticercosis has been reported as a wide spread and extremely common [49].

The results of present study also reflect economic importance of this disease, which is in agreement with the above statements. The prevalence of Cysticercus bovis among the carcasses inspected at Mekelle municipal abattoir was $4.44 \%$ which is lower than findings of Abay G [20] (7.23\%) in same area and 8.28\% and $5.36 \%$ reported earlier from same area by Abadi $M$ [52] at Alamata. This may be due to the fact that the prevalence of Cysticercosis bovis varies from country to country and also reflects the expertise meat inspectors.

The majority of the findings in Ethiopia were based on surveys carried out on carcasses subjected to the routine meat inspection procedures. Hence the same limitations with which meat inspection shares globally were reflected in this study. Accordingly the lower prevalence of bovine cysticercosis in this study might be attributed to improved personal and environmental hygiene, consumption raw meat might be lowered and method and quality of meat inspection may also be improved.

In contrast to low prevalence reported above, studies in export abattoirs like Mojo, ElLFORA, Dukem, Luna, revealed a comparatively higher prevalence of cysticercosis in cattle. The percent positivity in these abattoirs was $17.9 \%, 13.6 \%, 19.2 \%$ and $27.6 \%$ respectively [53].

From the above reports, it is evident that there is variation in the prevalence of Cysticercus bovis in cattle in Ethiopia. Grasey GF et al. [17] viewed that difference in the prevalence of cysticercosis with in a country probably reflects the difference in the expertise or 
diligence of meat inspector. In addition to this, the prevalence of cysticercosis is reported high in modern and export abattoir may be due to thorough meat inspection by incising all organs or muscles and also inspectors in such abattoirs are more experienced and also have awareness to the economic importance of Cysticercus bovis in the exportation.

Based on animal origin (highland and lowland) and age (two to five years and greater than five years) prevalence of Cysticercus bovis was also assessed and there was no any significant difference in the prevalence of cysticercosis between animals of highland and lowland origin and age (adult and old) ( $\mathrm{P}>0.05)$. Most of the cattle slaughtered during the study time were above 5 years age. As the age of animals' increases the susceptibility of animals for the diseases decreased, this is due to immunity.

The absence of significant difference between the origins of animals may be due to environmental condition of the areas and the feeding habit of the cattle. The lowland animal was brought from Afar area and while the highlands was brought from Amhara national regional state. The Afar region is the most pastoral area from Ethiopia and has hot climatic condition. The people of the area are nomadic; this hot and nomadic way of life will contribute for less contamination of the area with human feaces. This is because the ova and the graved proglotide can survive about 14 weeks to 6 months in marshy areas and wet seasons. The ova of Tania saginata and the graved proglotide are unable to survive in harsh environment [54].

The environmental conditions of the highland area were also less contaminated with human faeces. Since, they were brought from north Wollo, which is part of central highlands of Ethiopia. This area is not as such favorable for the egg of Tania saginata and gravid proglotide due to geographical feature of the area, which is too steepy and floody, not marshy during rainy season. The faeces and other sewages will simply floody to the lowland area. During dry season the gravid proglotide and the egg of Tania saginata will not survive for longer time as the environment is less contaminated with human faces [55].

The other risk factors analyzed during study period was body condition which is significant difference among them $(\mathrm{P}<0.05)$ indicating the higher likelihood of bovine cysticercosis occurrence in animals of poor body condition than medium and good body condition which is $17.27 \%, 3.64 \%$ and 3.455 respectively. This finding might be influenced by sample size proportion among them.

Regarding the anatomical distribution of the cysts, the organs affected in order of the proportion of the cysts were liver, lung, tongue, heart and masseter. The most frequently affected organ with the highest number of cysts was the liver (3.1\%) followed by lung $(0.7 \%)$, tongue $(0.4 \%)$, heart and masseter muscle $(0.2 \%)$. Cysticercus bovis are commonly found in muscles of mastication, particularly masseter muscles, shoulder muscles, heart, tongue, diaphragm and occasionally in fat, liver, lungs and lymph nodes. In the present study cysts were found in liver, heart, tongue, lungs and masseter muscles with a predominant prevalence in liver showing (3.1\%) out of 1800 cattle examined. A number of authorities now consider that there are no predilection sites of $C$. bovis and distribution of cysts is purely a mechanical phenomenon. From several properties variation and deviation and localization of cyst are possible

For example, in a study in Addis Ababa abattoir, the infection rate of Cysticercus bovis was a high as $16.3 \%$ in fore leg, $3, .7 \%$ in liver, and $1.6 \%$ in the lungs [56].

Similarly in East Shoa, Oromia regional state, an infection rate of $4.74 \%$ in liver and $0.7 \%$ in lungs were found [53].

Another reason of reporting higher percentage livers positivity for Cysticercus bovis infection is imperfect meat inspection facilities at Mekelle abattoir. In this abattoir, the organs and muscles for searching Cysticercus bovis are liver, hearts, lung, tongue, masseter muscles and triceps muscles. Even in these sites the number of incision made was limited (not more than one incision was not allowed). The other heavy muscles like fore legs, neck muscles, hind legs, and shoulder muscles never incised and inspected. This is because the butchers and owners usually oppose several incisions made during inspection, due to fear about loss of earnings. In this abattoir lack of facilities including electricity, may cause to loss the chance of getting cysts in different sites of striated muscle that are called "site of predilection".

Thorough examination of livers for various affections causes to increase the occurrence of Cysticercus bovis in livers. In most of reports in side Ethiopia as well other countries in the world showed that striated muscle "as the predilection site "for Cysticercus bovis

Hydatidosis and cysticercosis in cattle are economically significant because heavily infested carcasses or organs are to be condemned while cysts in low number are to be made inactive before being released for human consumption. In this study, high economic loss was reported due to hydatidosis and cysticercosis within an estimated annual loss of 930,918.52 ETB. Different economic losses regarding metacestodes were also reported from different parts of the country. Yilma F [57,58] reported annual loss of 


\section{Open Access Journal of Veterinary Science \& Research}

813,526.46 ETB at Debrezeit abattoir, [34] 90,646.95 ETB in Gonder, [39] 77, 587.02 ETB in Nekemte.

These differences of result in various abattoirs or regions may be due to variation in the prevalence of the disease mean annual slaughtered cattle in different abattoirs and variations in the retail market price of liver, lung, heart, kidney and beef.

\section{Conclusion and Recommendations}

The current study conducted on bovine metacestodes as major cause of economic loss due to organ condemnation, carcass weight loss, down graded carcasses in cattle slaughtered in Mekelle municipality abattoir revealed the economic importance of the disease in the study area. The economic impact caused by hydatidosis and cysticercosis was enormous in the study area. These differences of the result of economic losses due to the disease in various abattoirs/ regions may be due to the variation in the prevalence of disease, mean annual slaughtered cattle in different abattoirs and variation in the retail market price of carcasses and organs.

Based on this study and other facts about the prevalence and socio -economic impact of these diseases, the following recommendations are forwarded:

- There should be strict routine meat inspection so that infected organs and carcasses can be condemned accordingly and also backyard slaughtering of animals should be prohibited through designing and reinforcing of legislation, construction of slaughter houses which full fills the necessary facilities and implementation of proper meat inspection services.

- All condemned organs should be properly disposed in order to break the life cycle of some metacestodes like Echinococcus granulosus and stray dogs and cats must be prohibited from abattoirs and their number should also be systematically reduced.

- There should be public education to create awareness so that all consumers avoid consumption of raw meat and also able to use toilet.

- Promoting the establishment of intensive farms should be encouraged, since the management system practiced in the region is one factor in predisposing cattle to metacestods.

\section{References}

1. Ministry of Information, (2005) Export products of Ethiopia. Press Release of Ministry of information, Department of press and Audio visual-Addis Ababa.

2. Ogunrinade A, Adegoke GO (1982) Bovine fascioloscis in Nigeria. Intercurrent parasitic and bacterial infections. Trop Alm Hlth Pro 14(2): 121-125

3. Soulsby EJL (1982) Helminthes Arthropods and Protozoa of domestic Animals 7th(Edn.), pp. 90.

4. Bailliere Tindall London. Surroundings, southern Ethiopia. East Africa. Journal of public health 4(2): 73-79.

5. Macpherson CNL, Sporry A, Zeylie E, Roming T, Gorfe M (1989) Pastoralist and Hydatid disease: An ultrasound scanning prevalence survey in East Africa. Trans R Soc Trop Med Hyg 83(2): 243-247.

6. Shibiru T (1986) Introduction to Parasitology AAU press, pp: 160-166.

7. Henderix MC, Rebinson E (2006) Diagnostic Parasitology for Veterinary Technicians $3^{\text {rd }}$ (Edn.) Masby. Inc. China pp. 94-95.

8. MacManus DP, Smyth JD (1986) Hydatidosis: Changing concepts in Epidemiology and speciation. Parasitol Today 2(6): 163-168.

9. Schwabe CW (1986) Current statuses of Hydatid disease: A zoonosis of increasing importance. In Thompson RCA (Edn.) The biology of Echinococcus and Hydatid disease, London, UK, pp: 81-113.

10. Mersie A (1985) A survey of bovine hydatidosis and its public health importance in Sodo. FVM, AAU. Debrezeit Ethiopia, DVM thesis.

11. Obsa T (1988) Incidence and economics significance of hydatidosis at Asmara municipality abattoir. FVM, AAU, Debrezeit, Ethiopia, DVM thesis.

12. Melkamu T (1985) Preliminary study on echinococcusis or hydatidosis in cattle, sheep and goat in Gonder administrative region. FVM, AAU, Debrezeit, Ethiopia DVM thesis.

13. Gessess N (1991) Study of hydatidosis or echinococcusis in cattle slaughtered at Bahir Dar Municipality abattoir. FVM, AAU, Debrezeit, Ethiopia DVM thesis.

14. Hagos Y (1997) Hydatidosis/Echinococcosis: Prevalence and economic impact in bovine at Mekelle abattoir. Zoonosis and infection in dogs. FVM, AAU, Debrezeit, Ethiopia DVM thesis.

15. Eshete H, Bogale Y (1982) Echinococcosis infection in some animal hosts in Addis Ababa, Ethiopia. Med J Abstract. 


\section{Open Access Journal of Veterinary Science \& Research}

16. Jobire $Y$, Lobagho F, Tiruneh R, Abebe G, Dorchies $\mathrm{Ph}$ (1996) Hydatidosis in three selected regions in Ethiopia: an assessment trial and its prevalence, economic and public health importance. Revue Med vet 147(11): 797-804.

17. Payne WJA (1990) An introduction to animal husbandry in the tropics $4^{\text {th }}(\mathrm{Edn})$ Longerman Group limited, UK, Singapore 75-76.

18. Grasey GF, Collins, Huey RJ (1999) Disease caused by helminthes and arthropod parasite. Meat Hygiene 10 ${ }^{\text {th }}$ (Edn.) Saunders, UK, pp. 243-259, 635-699.

19. Mamo E (1988) some common zoonotic helminthes. In: Zein AZ, et al. (Eds), The ecology of health and Ministry of health, Addis Ababa pp. 231-143.

20. Abunna F (2007) Taeniasis and its socio-economic implication in Awasa town.

21. Abay G (2008) Study on prevalence of Cysticercus bovis and its public health importance at Mekelle municipal abattoir, MU, Mekelle, Ethiopia, DVM thesis.

22. BOPED (1998) Atlas of Tigray. Bureau of planning and economic development, national regional state of Tigray, Mekelle, Ethiopia, pp. 3-24.

23. FAO/ UNEP/ WHO, (1982) Guidelines for echinococcosis or hydatidosis surveillance, prevention and contro.FAO. Rome. 29: 147

24. Macpherson CNL (1985) Epidemiology and strain differentiation of Echinococcus granulosus in Kenya. University of London, php thesis.

25. WHO (1983) Guidelines for surveillance, prevention and control of taeniasis or Cysticercosis. Geneva, VPH, pp. 83-149.

26. ILCA, (1993) A hand book of African Livestock Statistics. Addis Ababa, Ethiopia.

27. Kassahun B (2008) Prevalence and economic significance of cystic hydatidosis in cattle slaughtered at Mekelle Municipality abattoir. FVS, MU, Mekelle, Ethiopia, DVM, thesis.

28. Polydorous K (1981) Animal health and economics case study: Echinococcosis with reference to Cyprus. Bull Int Epiz 93(5): 981-992.

29. Solomon H (1975) A brief analysis of activities of meat inspection and quarantine division. Department of Veterinary Services, MOA, Ethiopia, pp. 35
30. Kipkorir KP (1998) Prevalence and strain differentiation of Echinococcus granulosus in some selected site of Ethiopia.

31. Arene FOI (1985) Prevalence of hydatidosis in domestic livestock in the Nigeria. Delta Trop Asnim Hlth Prod 17(1): 3-4.

32. Tsegaye M (1995) Epidemiology of bovine fasciolosis and hydatidosis in Debra Berhan region .FVM, AAU, Debre Zeit, Ethiopia, DVM Thesis.

33. Mohammed A (1985) Prevalence of Echinococcos granulosus among domesic animals in Libiya. Trop Anion Hlth Prod 17(3): 169-170.

34. ELISA AM, Mustafa AA, Solima KN (1985) A preliminary report on Cysticercosis and hydatidosis in Southern Sudan. Sud. J Vet Sc Anima Hlth 3(2): 79-108.

35. Roman T (1987) Study on economic significance of bovine fascilosis and hydatidosis at Gonder abattoir. FVM, AAU, Debre Zeit, Ethiopia, DVM thesis.

36. Temane M (1986) A preliminary study on echinococcosis/hydatidosis of livestock/cattle, Sheep and Goats in Gonder administrative region. FVM, AAU, Debrezeit, Ethiopia, DVM Thesis.

37. Onyango-Abuje JA, Hughes G, Opicha M, Nginyi KM, Rugutt MK, et al. (1996) Diagnosis of Tania saginata cysticercosis in Kenya cattle by antibodies and antigen ELISA. J vet Parasitol 66: 221-230.

38. Asrat G (1996) Prevalence and economic significance of hydatidosis /echinococcosis slaughtered cattle, sheep and Goats in south Wollo. FVM, AAU, Debrezeit, Ethiopia, DVM thesis.

39. Feyissa L (1987) Prevalence of hydatidosis at Nekemte municipality slaughter house. FVM, AAU, Debrezeit, Ethiopia, DVM thesis.

40. Bersisa K (1994) Hydatidosis in Nekemte, Prevalence in slaughtered cattle and sheep, estimated economic loss and incidence in stray dogs. FVM, AAU, Debrezeit, Ethiopia, DVM thesis.

41. Getachew J (1991) The prevalence of Hydatidosis in cattle at Awasa abattoir. FVM, AAU, Debrezeit, Ethiopia, DVM thesis.

42. Feseha G, Yilma J (1984) Preliminary study of economic and public health Significance of echinococcosis in Ethiopia $3^{\text {rd }}$ scientific journal. 


\section{Open Access Journal of Veterinary Science \& Research}

43. Alemayehu I (1990) The prevalence of hydatidosis in cattle, sheep, goat and Echinococcus granulosus in dogs in Arsi administrative region FVM, AAU, Debrezeit, Ethiopia, DVM thesis.

44. Nebiyou G (1990) Study of hydatidosis/ echinococcosis in cattle slaughtered at Bahir Dar municipality abattoir. FVM, AAU, Debre Zeit, Ethiopia, DVM thesis.

45. Wubet S (1988) Prevalence of cattle hydatidosis and its economic significance in Robe municipality abattoir. FVM, AAU, Debrezeit, Ethiopia, DVM thesis.

46. Gedlu I (1991) Prevalence of hydatidosis around Ticho- Robe IRA, fourth international livestock conference, Addis Ababa, Ethiopia.

47. Fikre I (1994) Echinococcosis or hydatidosis in Konso (Southern Ethiopia); an assessment trial of its prevalence, economic and public health significance. FVM, AAU, Debrezeit, Ethiopia, DVM thesis.

48. Matosian RM (1997) Hydatidosis: A slab problem of increasing importance, Bull, WSW. 5. Pp: 499 507.

49. Gracey IE (1986) Meat hygiene, $8^{\text {th }}$ (Edn.), London, Baillie Tindall Pp: 517.

50. Urquahart GM, Armour JL, Duncan AM, Dunny AM, Jennings FM (1996) Veterinary Parasitology, 2nd (Edn.) Black well science, UK, pp. 257-271.

51. Organization of international epizootic report of (OIE, 2004).
52. Fan PC (1997) Annual economic loss caused by Taenia saginata taeniasis in East Asia. Parasitol Todays 13(5): 194-235.

53. Abadi M (2009) Study on prevalence of Cysticercus bovis and its public health importance at Alamata municipal abattoir, CVM, MU, Mekelle, Ethiopia, DVM thesis.

54. Degefu H (2005) Introduction to Animal Parasitology $3^{\text {rd }}$ (Edn.), Cambridge University press, London, UK, Pp. 809.

55. Dawit S (2004) Epidemiology of Tania Saginata Taeniasi and Cysticercosis in North Gonder Zone North West Ethiopia. FVM, AAU, Debrezeit, Ethiopia, DVM thesis.

56. EFSA (2006) Opinion of the scientific panel on Biological Hazard (BIHAZ) and of scientific panel on animal Health and Welfare (AHAW) "On review of community summary report on trends and sources of zoonoses, zoonotic agents and antimicrobial resistance in the European Union in 2004". Adapted 7 and 8 September htt:/ www.efsa.Europe. Eu/etc medialib/ efsa/ science /biohaz/ boas Opinions/ biohazahaw- ej 403zoonoses. Par. 0001.File. Dat/biohazhaw- op- ej 403- zoonoses- en. Pdf.

57. Gebreab F (1995) Zoonotic Disease in Ethiopia. Ethiopia society of Animal production (ESAP), Addis Ababa, pp. 32-37.

58. Yilma F (1984) Prevalence of cattle hydatidosis and its economic significance in Debrezeit municipality abattoir. FVM, AAU, Debrezeit, Ethiopia, DVM thesis. 